\title{
Economia do compartilhamento de infraestruturas no setor de telecomunicações brasileiro: inventário e o desenho de um mecanismo geral de compartilhamento
}

Revista Latinoamericana de Economía y Sociedad Digital

Issue 1 , agosto 2020

Autores: Luciano Charlita de Freitas (iD), Tiago Sousa Prado(D), Agostinho Linhares De Souza $\underline{\text { Filho }}{ }^{(\mathbb{D}}$, Ronaldo Neves de Moura Filho $^{(\mathbb{D}}$, Carlos Manuel Baigorri ${ }^{(\mathbb{D}}$, Leonardo Euler de Morais

DOI: $10.53857 /$ DMTI9200

Publicado: 10 agosto, 2020

Cita sugerida: Charlita De Freitas, Luciano; Tiago Sousa Prado, Agostinho Linhares De Souza Filho, Ronaldo Neves De Moura Filho, Carlos Manuel Baigorri, Leonardo Euler De Morais (2020) "Economia do compartilhamento de infraestruturas no setor de telecomunicações brasileiro: inventário e o desenho de um mecanismo geral de compartilhamento" en Revista Latinoamericana de Economía y Sociedad Digital, Issue 1

Licencia: Creative Commons Atribución-NoComercial 4.0 Internacional (CC BY-NC 4.0)

Tipo: Ensayo

Palabras clave: Compartilhamento de Infraestruturas, Desenho Geral de Mecanismo, General Mechanism Design, Infrastructure Sharing, Telecommunications, Telecomunicações

\section{Resumen}

La infraestructura de telecomunicaciones es el insumo fundamental para la prestación de servicios de voz y datos. Durante las dos décadas posteriores a la privatización del sector, las inversiones dirigidas al sector se orientaron principalmente a ampliar la disponibilidad de infraestructura, motivadas principalmente por estrategias competitivas u obligaciones regulatorias. Sin embargo, a principios del siglo actual, las limitaciones en la capacidad de inversión, los desafíos de rentabilidad y la armonización técnica mejorada han alentado el despliegue de modelos de intercambio de infraestructura destinados a mejorar la asignación de activos escasos y reducir los costos operativos. Este estudio propone inventariar los principales mecanismos de intercambio disponibles en el sector de telecomunicaciones 
brasileño y, luego, establecer un modelo general de intercambio. Sobre la base de dicho marco, explora el potencial de las soluciones compartidas como instrumento para mejorar la competencia, la eficiencia en la asignación de recursos escasos y maximizar el bienestar social.

\section{Abstract}

Telecommunications infrastructure is the fundamental input for the provision of voice and data services. Over the two decades following of the sector's privatization, investments addressed towards the sector were mainly turned to expanding infrastructure availability, mainly motivated by competitive strategies or regulatory obligations. However, at the turn of the current century, constraints on investment capacity, profitability challenges and improved technical harmonization have encouraged the deployment of infrastructure sharing models aimed at improving the allocation of scarce assets and reducing operating costs. This study proposes to inventory the main sharing mechanisms available in the Brazilian telecommunications sector and, then, to set up a general sharing model. Based on such a framework, it explores the potentials of the sharing solutions as an instrument to improve competition, allocative efficiency of scarce resources and to maximize social wellbeing.

\section{Resumo}

As infraestruturas de telecomunicações são insumos fundamentais para prestação de serviços de voz e dados. Nas duas décadas que seguiram a privatização do setor no Brasil os investimentos oram majoritariamente endereçados para a ampliação da infraestrutura, motivado por fatores econômicos, a maioria de ordem competitiva, ou obrigações regulatórias. Porém, na virada do atual século, restrições relacionadas à capacidade de investimento, rentabilidade dos negócios e harmonizações de ordem técnica criaram incentivos para a adoção de modelos de compartilhamento, com vistas a reduzir a ociosidade dos ativos escassos e otimizar os custos de operação. Este estudo propõe inventariar os principais mecanismos de compartilhamento em uso no setor de telecomunicações brasileiro e, em seguida, a partir de suas características fundamentais, propor o desenho de um modelo geral de compartilhamento. Ao cabo, são propostas contribuições acerca como medida de promoção competição, melhoria da eficiência alocativa de recursos escassos e para maximização do bem-estar social.

\section{Introdução}

O compartilhamento de infraestruturas compreende a cessão, para terceiros, de ativos 
utilizados na prestação de serviços de utilidade pública. Tem por finalidade a busca por maior eficiência na alocação de recursos escassos, essenciais à prestação de serviços, e otimização de custos com investimentos e operação.

Arranjos de compartilhamento entre prestadores de serviços de telecomunicações figuram entre as mais sofisticadas iniciativas de cooperação interempresarial. Seu uso remonta ao período da abertura do mercado na década de 1990, quando soluções de compartilhamento mandatórias foram estabelecidas em Lei e, mais tarde, em regulamentos.

A partir dos anos 2000, novos modelos de compartilhamento espontâneos se difundiram no Brasil. Contribuiu para essa mudança o reconhecimento de que a diferenciação pela cobertura ou propriedade das infraestruturas, estratégias dominantes nos períodos iniciais de universalização dos serviços, foram suplantadas por iniciativas orientadas à diferenciação por preço e qualidade e pela busca por maior eficiência alocativa e redução de custos. Esse posicionamento tornou-se um componente essencial para a subsequente expansão dos serviços de telefonia e banda larga para regiões de menor retorno sobre investimento, localizadas em franjas urbanas, periferias e áreas rurais e remotas do país.

A argumentação em favor do compartilhamento também tem respaldo em avanços técnicos relacionados à padronização de tecnologias e protocolos de comunicação (Meddour et al. 2011, Sidenbladh 2002). Nesses termos, experiências de compartilhamento de sites e antenas utilizadas para comunicações móveis sugerem potencial de redução de custos de capital de até 30\% e dos custos operacionais de até 45\% (Lefèvre 2008, Meddour et al. 2011).

No contexto em que este estudo é elaborado, marcado pela pandemia do coronavírus, as soluções de compartilhamento ganham especial ênfase. Isso porque, tal mecanismo, por ser habilitador da otimização de custos, permite compatibilizar o crescimento excepcional da demanda por conectividade e intensidade do uso das redes de telecomunicações à crise de liquidez deflagrada no setor.

O presente estudo tem o duplo objetivo de inventariar os principais arranjos de compartilhamento em uso no setor de telecomunicações brasileiro e desenhar um modelo geral de compartilhamento que possibilite analisar, de modo sistematizado, as relações entre os agentes envolvidos. No tocante ao inventário, compreende o mapeamento de seus fundamentos legais e regulatórios, suas características principais, as motivações e suas restrições, entre outros.

Sobre o modelo geral, o mesmo é desenvolvido à luz das características identificadas nos principais arranjos de compartilhamento. Tem como propósito evidenciar as propriedades de um mecanismo de compartilhamento genérico e elucidar suas limitações e desafios. Tal exercício, elaborado a partir de abordagens modernas da teoria dos jogos, com destaque para as teorias de contratos e de mechanism design, assume como problema central a busca pela maior utilidade dos participantes, restrito à quantidade de recursos que estariam 
dispostos a ceder para conformação do ativo a ser compartilhado e a parcela do seu custeio.

Para assegurar um debate coerente com a prática, o estudo está organizado em três partes. A seção a seguir trata dos aspectos regulatórios e econômicos que subsidiam a decisão pelo compartilhamento de infraestruturas no setor de telecomunicações. Em seguida, é apresentado o inventário das principais soluções de compartilhamento, com as respectivas referências normativas e legais e seus componentes essenciais. A seção seguinte trata do desenho do mecanismo geral de compartilhamento, adotando-se como referência um arranjo hipotético entre dois agentes independentes e sem conluio. Por fim, são apresentados argumentos sobre o impacto e a importância de soluções de compartilhamento para fins de desenho de políticas públicas e as principais conclusões do estudo.

\section{Aspectos regulatórios e econômicos do compartilhamento de infraestruturas no setor de telecomunicações}

Soluções de compartilhamento de infraestrutura consistem nos mais modernos instrumentos de otimização de custos no setor de telecomunicações. Relatos de Garcia e Kelly (2015) sugerem que aplicações de compartilhamento em países africanos permitiram reduzir o custo médio da operação e incluir consumidores de regiões com menor atratividade econômica. Por sua vez, no estudo conduzido por Markendahl (2011), fundamentado em entrevistas com prestadores, são elencados entre os benefícios do compartilhamento, a melhoria do posicionamento de mercado, o aumento da cobertura, a redução dos custos operacionais de manutenção de rede, a disponibilidade de radiofrequências para pequenos prestadores ou novos entrantes, a expansão dos negócios para novos mercados, entre outros.

A opção pelo compartilhamento no Brasil sucedeu um paradigma dominante no setor de telecomunicações, respaldado na independência na propriedade e exclusividade no uso da infraestrutura como vantagem competitiva. Tal concepção, foi desafiada pela redução sucessiva das receitas médias por usuário, provocada pela crise do ambiente de negócios no Brasil, pelo efeito substituição dos serviços tradicionais e pelo padrão de competição setorial e a percepção de que a provisão de cobertura e capacidade já não constituía diferencial competitivo no setor (Aguiar et al. 2016).

Nesse novo ambiente, os agentes econômicos vislumbraram no compartilhado de infraestruturas uma solução viável para o desenvolvimento dos seus negócios. Seus incentivos se orientam, por um lado, pelo uso mais intensivo da infraestrutura compartilhada e, por outro, pela redução dos custos de composição e manutenção dessas infraestruturas.

Nessas bases, difundiram-se acordos de compartilhamento cujos objetos abrangem desde os 
elementos mais fundamentais da chamada última milha, até sofisticados acordos de cooperação em investimentos e compartilhamento de radiofrequências. Tais soluções são formuladas sobre princípios comuns, equiparáveis do ponto de vista negocial e estratégico, e pelos incentivos que induzem os agentes econômicos a se engajarem nesses modelos.

O compartilhamento de infraestruturas de telecomunicações móveis posiciona-se entre as soluções mais arrojadas. Essa tecnologia é reconhecida pelo menor custo marginal e é base para a prestação de serviços essenciais, inclusive de banda larga móvel, compreendida como um dos meios viáveis de massificação do acesso para a maior parte da população (Lefèvre 2008), inclusive entre as famílias de baixa renda relativa (Freitas et al. 2018).

Regiões rurais, menos populosas, ou periferias dos grandes centros urbanos são particularmente beneficiadas por essa estratégia. Nessas áreas, o compartilhamento de infraestrutura pode viabilizar a disponibilização e manutenção das redes, atenuar as limitações econômicas associadas ao poder de consumo e, desse modo, ampliar a cobertura dos serviços de telecomunicações. O mesmo raciocínio pode justificar a ampliação da competição no setor.

A intervenção regulatória em benefício do compartilhamento de infraestruturas se justifica por seu potencial impacto sobre a competição e ganhos de eficiência decorrente da racionalização do fluxo de investimentos para o setor. Regulamentos que tratam de compartilhamento também fazem referência à otimização de custos e eficiência do uso de recursos escassos, efeitos sobre a cobertura e qualidade dos serviços.

Alguns tipos de compartilhamentos que possibilitam, por exemplo, a entrada de novos competidores ou a separação funcional e estrutural das redes podem também facilitar a promoção de infraestruturas de acesso e o avanço da competição. Esses arranjos são, usualmente, precedidos de um amparo regulatório e oferecem particular benefício a mercados emergentes.

\section{Inventário de arranjos de compartilhamento de infraestruturas no contexto brasileiro}

Esta seção apresenta uma abordagem sucinta sobre as principais soluções de compartilhamento de infraestruturas no setor de telecomunicações no Brasil. A tecnicidade foi deliberadamente delimitada em benefício de uma compreensão mais abrangente sobre as práticas de compartilhamento. Referências adicionais são providas de modo a facilitar estudos futuros sobre cada arranjo indicado.

Alguns aspectos fundamentais das soluções inventariadas dizem respeito à predominância de ativos privados, o interesse econômico de sua exploração em regime de compartilhamento e a busca por eficiência alocativa desses recursos. Além disso, por se tratarem de recursos escassos e essenciais para a prestação do serviço, o 
compartilhamento, em regra, se circunscreve à capacidade excedente da infraestrutura.

As características indicadas para cada solução de compartilhamento inventariadas derivam da análise estruturada de regulamentos e contratos públicos disponíveis. Abrangem questões de ordem regulatória, de governança e custeio, bem como diretrizes de ordem competitiva. A tabela a seguir resume as características dos arranjos.

Tabela 1. Inventário e caracterização dos arranjos de compartilhamento do setor de Telecomunicações 
Tabela 1. Inventário e caracterização dos arranjos de compartilhamento do setor de Telecomunicações

\begin{tabular}{|c|c|c|c|c|c|c|}
\hline Características & $\begin{array}{c}\text { Inter-cone } \\
\text { xão }\end{array}$ & $\begin{array}{l}\text { Infra-estr } \\
\text { uturas } \\
\text { multi--set } \\
\text { orial }^{2}\end{array}$ & $\begin{array}{l}\text { Roaming } \\
\text { Unbundling } \\
\text { Linha } \\
\text { Dedicada }^{5} \\
\text { Dutos }\end{array}$ & MVNO & $\begin{array}{c}\text { RAN } \\
\text { Sharing }\end{array}$ & $\begin{array}{c}\text { Infra-estru } \\
\text { tura de } \\
\text { suporte }\end{array}$ \\
\hline Afeta a competição? & प्व & प्व & प्व & प्वाप & ㅁㅁㅁ & प्व \\
\hline $\begin{array}{l}\text { Recurso compartilhado é } \\
\text { escasso? }\end{array}$ & प्व & प्व & प्व & प्व & ㅁㅁㅁ & $\square \square$ \\
\hline $\begin{array}{l}\text { Compartilhamento } \\
\text { mandatório? }\end{array}$ & प्व & Não & प्व & Não & Não & Não \\
\hline $\begin{array}{ll}\text { Existe } & \text { regulamento } \\
\text { específico? }\end{array}$ & प्व & प्व & प्वप & प्व & Não & प्व \\
\hline $\begin{array}{l}\text { Exige anuência prévia da } \\
\text { oferta pública? }\end{array}$ & प्व & Não & प्व & Não & Não & Não \\
\hline $\begin{array}{l}\text { Exige transparência das } \\
\text { ofertas públicas? }\end{array}$ & प्व & प्व & प्व & Não & Não & प्व \\
\hline $\begin{array}{l}\text { Específico para o setor de } \\
\text { telecomunicações? }\end{array}$ & प्व & Não & प्वप & प्व & प्व & Não \\
\hline Estabelece teto de preços? & ㅁㅁ & Não & $\square \square$ & Não & Não & Não \\
\hline $\begin{array}{l}\text { Exige padrões técnicos, de } \\
\text { qualidade e segurança? }\end{array}$ & (ם & प्व & प्व & प्व & प्व & प्व \\
\hline
\end{tabular}

\footnotetext{
${ }^{1}$ Resolução $\mathrm{n}^{\circ} 693$, de 17 de julho de 2018.

${ }^{2}$ Resolução Conjunta n ${ }^{\circ}$ 1, de 24 de novembro de 1999 (Aneel, Anatel e ANP).

${ }^{3}$ Resolução n ${ }^{\circ}$ 694, de 17 de julho de 2018.

${ }^{4}$ Resolução n ${ }^{\circ} 694$, de 17 de julho de 2018.

${ }^{5}$ Resolução n 694, de 17 de julho de 2018.

${ }^{6}$ Resolução $n^{\circ} 694$, de 17 de julho de 2018.

${ }^{7}$ Resolução $\mathrm{n}^{\circ}$ 550, de 22 de novembro de 2010.

${ }^{8}$ Processos n ${ }^{\circ} 53500.017260 / 2015-34, n^{\circ} 53500.017260 / 2015-34, n^{\circ} 53500.001089 / 2014-61, n^{\circ} 53500.011812 / 2018-43$.

${ }^{9}$ Resolução n ${ }^{\circ} 683$, de 05 de outubro de 2017.
} 


\begin{tabular}{|c|c|c|c|c|c|c|}
\hline $\begin{array}{lr}\text { Sujeito a sanções } & \text { por } \\
\text { descumprimento } & \text { ou } \\
\text { abuso? } & \end{array}$ & $\square \square \square$ & ㅁㅁㅁ & $\square \square \square$ & Não & Não & $\square \square \square$ \\
\hline $\begin{array}{lr}\text { Estabelece } & \text { padrões } \\
\text { ambientais } & \text { e/ou } \\
\text { urbanísticos? } & \end{array}$ & Não & प्वप्र & Não & Não & Não & प्वप \\
\hline $\begin{array}{l}\text { Tratamento Isonômico e } \\
\text { não discriminatório? }\end{array}$ & $\square \square$ & $\square \square \square$ & $\square \square \square$ & Não & Não & $\square \square$ \\
\hline $\begin{array}{l}\text { Exige anuência prévia do } \\
\text { Regulador? }\end{array}$ & ㅁㅁㅁ & ㅁㅁㅁ & $\square \square \square$ & Não & $\square \square \square$ & $\square \square \square$ \\
\hline $\begin{array}{l}\text { Exige anuência prévia do } \\
\text { órgão de antitrust? }\end{array}$ & Não & Não & Não & Não & Não & Não \\
\hline Exige contratação? & $\square \square \square$ & ㅁㅁㅁ & $\square \square \square$ & $\square \square \square$ & $\square \square$ & $\square \square$ \\
\hline É oneroso? & $\square \square$ & प्वप्र & $\square \square$ & प्व & $\square \square$ & $\square \square$ \\
\hline $\begin{array}{l}\text { Termos do contrato são } \\
\text { sigilosos? }\end{array}$ & Não & $\square \square \square$ & ㅁㅁㅁ & $\square \square \square$ & $\square \square \square$ & $\square \square \square$ \\
\hline $\begin{array}{lr}\begin{array}{l}\text { Cláusula } \\
\text { compartilhamento }\end{array} & \text { de } \\
\text { custos? } & \\
\end{array}$ & Não & Não & ㅁㅁㅁ & $\square \square \square$ & Não & $\square \square \square$ \\
\hline Exige custo de associação? & Não & Não & Não & Não & Não & $\square \square$ \\
\hline $\begin{array}{l}\text { Custo variável por volume } \\
\text { de uso? }\end{array}$ & $\square \square \square$ & $\square \square \square$ & $\square \square \square$ & $\square \square \square$ & $\square \square \square$ & $\square \square$ \\
\hline Duração limitada? & $\square \square$ & $\square \square \square$ & $\square \square$ & $\square \square$ & $\square \square \square$ & $\square \square$ \\
\hline Exige reciprocidade? & Não & Não & Não & Não & $\square \square \square$ & Não \\
\hline $\begin{array}{l}\text { Prevê instância para } \\
\text { resolução de conflitos? }\end{array}$ & प्व & प्वप्र & प्व & Não & प्व & $\square \square$ \\
\hline $\begin{array}{l}\text { Presença de um } \\
\text { coordenador } \\
\text { independente? }\end{array}$ & Não & Não & Não & Não & Não & Não \\
\hline $\begin{array}{l}\text { Restrição por área } \\
\text { geográfica ou limitação } \\
\text { técnica? }\end{array}$ & $\square \square \square$ & Não & $\square \square \square$ & Não & Não & $\square \square \square$ \\
\hline
\end{tabular}

Elemento essencial do inventário remete à origem voluntária, ou mandatória, dos arranjos de compartilhamento. Soluções mandatórias, reguladas parcial ou integralmente por legislação ou normas infralegais, são, em regra, justificadas pelo uso de recursos escassos, ou pela necessidade de se mitigar eventual ocorrência de abusos de poder de mercado. 
Conforme será delineado na seção a seguir, arranjos com mediação de um agente central são, sob a perspectiva de eficiência de Pareto, do tipo second-best e exigem, para seu adequado funcionamento, a intervenção por meio de regras contratuais ou poder de atuação e arbitragem para assegurar o correto funcionamento do sistema. De qualquer sorte, são essenciais para o desenvolvimento do setor e compõem, para o caso brasileiro, a maior parte dos arranjos de compartilhamento.

Dos mecanismos mandatórios inventariados, o mais notório e difundido é a interconexão. Do histórico normativo afere-se que o Poder Público, desde os primeiros tempos de exercício das competências do órgão regulador, voltou-se ao tratamento da matéria, nos termos do regulamento aprovado pela Resolução no 40/1998 (Anatel 1998). Posteriormente, a evolução setorial e, em resposta, os avanços regulatórios, atualizaram duas vezes essa regulamentação nos termos da Resolução no 410/2005 (Anatel 2005) e da atualmente vigente Resolução nํ 693/2018 (Anatel 2018).

Esta última, em vigor, trata dos princípios e regras básicas de operacionalização. Sua obrigatoriedade remete à Lei Geral de Telecomunicações (LGT) (Brasil 1997) que estabeleceu sua obrigatoriedade. Em síntese, a interconexão possibilita a integração das infraestruturas como vias de livre circulação. A intenção do legislador, ao tornar obrigatória a interconexão, e do regulador, ao regular esse mecanismo, foi assegurar a criação de um ambiente concorrencial, pautado na integração das infraestruturas, em substituição à opção pela criação de várias redes distintas e autônomas (Laender 2002).

A expectativa do legislador à época da edição da lei geral, conforme consta dos artigos 146 e 155 da LGT, era que a adoção da obrigação de compartilhamento permitiria mitigar barreiras competitivas associadas à notória escassez de infraestruturas (Nascimento 2013). Preponderava naquele contexto a percepção de que os titulares das infraestruturas não estariam dispostos a ceder, por livre iniciativa, o insumo essencial à prestação do serviço de telecomunicações aos seus competidores (Nascimento, 2013).

A evolução regulatória e do mercado também criou condições para arranjos de cooperação intersetorial. Por exemplo, a Resolução Conjunta no 1/1999 (Anatel 1999) estabeleceu as bases para o compartilhamento de dutos, condutos, postes e torres, cabos metálicos, coaxiais e fibras ópticas entre concessionários dos setores de telecomunicações, energia e petróleo.

Tal arranjo abrange agentes e reguladores de serviços públicos de energia elétrica, de telecomunicações e os serviços de transporte dutoviário de petróleo. À exemplo das demais soluções de compartilhamento abordados neste estudo, o compartilhamento dos recursos objeto da Resolução Conjunta se aplicam à capacidade excedente e figura entre as soluções com maior intensidade de uso no setor.

Referências sobre o desempenho do compartilhamento sob alçada da Resolução Conjunta $\mathrm{n}^{\underline{0}}$ 1/1999 revelam particular limitação no tocante ao uso compartilhado de postes. Tal recurso, 
cuja titularidade é, predominantemente, dos distribuidores de energia elétrica, tem no setor de telecomunicações seu uso mais intensivo uma vez que se constitui meio de passagem dos mais variados serviços de voz e dados prestados sob meios físicos. A escassez desse recurso exacerbou os casos de conflitos e, por conseguinte, das demandas por arbitragem entre os reguladores envolvidos (Samanez 2018, LCA 2018).

Em geral, observa-se a predominância por soluções onerosas, de duração limitada, passível de renovação, e regida por contratos bilaterais. Com menor incidência, constata-se a exigência de anuência prévia, por órgãos reguladores, que ocorre, com maior incidência, em homologações contratuais ou atesto preliminar sobre aspectos de compliance com de regulamentos de competição e correlatos.

Em adição, verifica-se a ocorrência de arranjos onerosos quando o titular do recurso é remunerado por um terceiro, usuário da infraestrutura compartilhada. Essa compensação ocorre, principalmente, com valores orientados a custos, em obediência ao Decreto nํㅜ 4.733/2003, que dispõe sobre políticas públicas de telecomunicações, e que determinou a adoção de modelo de custo de longo prazo na definição das tarifas de interconexão e nos preços de disponibilização de elementos de rede (Presidência da República 2003).

Alternativamente, quando se trata de temas afetos ao uso de radiofrequências, observa-se uma predominância por compartilhamento com cessão equivalente de recursos entre os associados. Tal sistemática se manifesta com maior frequência em arranjos do tipo RAN Sharing, estabelecidos a partir do princípio de reciprocidade de uso de recursos.

Os arranjos de roaming, unbundling, linhas dedicadas e dutos são soluções técnicas de integração de redes de telecomunicações. São estabelecidas sob princípios e diretrizes de compartilhamento definidos nos termos da Resolução nº 694/2018 (Anatel 2018b). A importância deste regulamento, balizador de diversos mecanismos de compartilhamento no setor, revela o comprometimento do regulador setorial face ao tema de compartilhamento. Tal compromisso, para fins de referência, foi confirmado nos termos do manual operacional de compartilhamento de infraestrutura (Anatel 2019), que estabeleceu um sistema eletrônico de propostas públicas de compartilhamento e que contempla, entre outros, critérios para composição de preços e prazos para compartilhamento desses recursos.

O roaming permite compatibilizar a coordenação de radiofrequências de modo a possibilitar a conectividade para usuários visitantes de outras redes de telecomunicações móvel. Por sua vez, o unbundling e as linhas dedicadas são soluções de integração de redes físicas de telecomunicações de voz e dados. O uso efetivo desses arranjos possibilita ampliar a cobertura dos serviços entre prestadores concorrentes.

Por sua vez, o chamado Mobile Virtual Network Operator (MVNO), traduzido no plano regulatório brasileiro como Rede Virtual, é uma solução voluntária, regulamentada por meio da Resolução no 550/2010 (Anatel 2010). Abrange o conjunto de processos, sistemas, equipamentos e demais atividades utilizadas pelo credenciado ou pela autorizada de Rede 
Virtual para a exploração de SMP por meio da rede da prestadora de origem. A autorização de Rede Virtual para prestação do Serviço Móvel Pessoal utiliza o compartilhamento de rede com a prestadora origem. Por sua vez, o credenciamento trata de contrato de representação, objeto de livre negociação entre o credenciado e a prestadora de origem, cuja eficácia depende de homologação por parte do regulador de telecomunicações.

Dentre os arranjos de compartilhamento formulados a partir de iniciativa privada e, portanto, desvinculados de obrigatoriedades regulatórias, destaca-se o RAN Sharing. Tal solução técnica, em sua configuração mais abrangente, permite o compartilhamento de elementos de acesso na rede de rádio, inclusive de radiofrequências, além de elementos do núcleo de rede das prestadoras, como nos casos de soluções MORAN (Multiple Operator Radio Access Network) e MOCN (Multiple Operator Core Network).

Os termos gerais que autorizam o compartilhamento na prestação do Serviço Móvel Pessoal (SMP) estão previstos na Resolução no 477/2007 que trata do Regulamento do Serviço Móvel Pessoal (Anatel 2007) e na Resolução nํ 671/2016, que diz respeito ao Regulamento de Uso do Espectro (Anatel 2016). Avanços nas soluções de RAN Sharing no Brasil estão relacionados à substituição de tecnologias legadas de $2 \mathrm{G}$ e a ampliação da malha de cobertura móvel no interior do país. Em função dos efeitos sobre a competição, estabeleceuse uma sistemática de anuências prévias para os acordos de RAN Sharing que são expedidas após extensiva análise de impacto competitivo pelo regulador.

O compartilhamento de infraestruturas de suporte é outra solução com ampla repercussão no setor. A despeito de sua origem como iniciativa voluntária do mercado, foi incorporado ao regime regulatório brasileiro, na forma da Resolução nº 683/2017 (Anatel 2017). O regulamento abrange postes, torres, mastros, armários, dutos, condutos, estruturas de superfície e estruturas suspensas.

A despeito de inexistir obrigação de submissão desses arranjos ao órgão antitrust brasileiro, o Conselho Administrativo de Defesa Econômica - CADE, diversos contratos com esses modelos foram por ele avocados. Em geral, arranjos dessa natureza são qualificados, na perspectiva do CADE, como contrato associativo, nos termos da Resolução no 17/2016 (Cade 2016). Tal designação é definida para quaisquer contratos com duração igual ou superior a 2 anos que estabeleçam empreendimento comum para exploração de atividade econômica, desde que, cumulativamente estabeleça o compartilhamento dos riscos e resultados da atividade econômica que constitua o seu objeto e que as partes contratantes sejam concorrentes no mercado relevante objeto do contrato. Uma vez confirmada essas características, passa a ser exigência do órgão de antitrust sua anuência prévia para renovação do contrato, e a continuidade da sua vigência por prazo igual ou superior a dois anos dependerá da aprovação prévia do CADE.

O compartilhamento obrigatório de dutos figura entre as mais recentes iniciativas do regulador em favor da promoção da competição no mercado de infraestruturas essenciais. Esse mercado é caracterizado pela alta concentração e baixa competição o que, por um lado 
inviabiliza a entrada de novos competidores, e, por outro, impede seu correto dimensionamento. Nas condições impostas pelo regulador, os detentores de mercado significativo passam a ser obrigados a declarar a extensão e disponibilidade da rede de dutos e oferecê-lo, com um valor de referência orientado a custos, mediante vigilância do regulador setorial (Anatel 2018b).

\section{Modelo geral de compartilhamento de infraestruturas}

As características comuns dos arranjos de compartilhamento permitem conceber o desenho de um mecanismo geral cuja utilidade se justifica pela possibilidade de compreender seu funcionamento, identificar os pontos críticos e antecipar medidas de mitigação de riscos à competição, ineficiência no uso de recursos escassos e a adoção de iniciativas de maximização do bem-estar. O problema central do mecanismo geral proposto é a defesa do interesse individual dos participantes sobre a quantidade de recursos que estariam dispostos a ceder para formatação do modelo e, a parcela variável do seu custeio.

Nesses termos, deve-se reconhecer que a opção pelo compartilhamento pressupõe a existência de $n$ organizações associadas com o desejo comum de otimizar a alocação de seus recursos. Nessas circunstâncias, o objetivo é identificar a maior soma possível da utilidade dos agentes, um problema típico do mechanism design (Fudenberg e Tirole 1991).

Assim, o mecanismo geral formulado para o presente estudo é elaborado a partir de premissas de maximização da utilidade geral de um sistema de compartilhamento. A modelagem utiliza como referências fundamentais os estudos de Courcoubetis e Weber (2009), Nisan et al. (2001), Myerson (2008). Especificamente, faz uso extensivo da formulação elaborada por Courcoubetis e Weber (2009) em estudo sobre compartilhamento de soluções de redes virtuais, computação em grid e processamento na nuvem, com as devidas adaptações para o contexto dos arranjos de compartilhamento em uso no setor de telecomunicações brasileiro.

Nesse tipo de problema, cada uma das organizações envolvidas possui expectativas distintas sobre o uso da infraestrutura compartilhada e com base nelas estabelecem referências sobre seus custos e benefícios. Assim, uma determinada organização i que obtenha direito de uso compartilhado da infraestrutura xi, a um custo ci, espera obter benefícios uxi, na forma de incremento de receitas, redução de custos ou ampliação da cobertura da prestação de seus serviços, por exemplo.

Os pagamentos ci são constantes no tempo e, não necessariamente, em moeda. Abrangem, por exemplo, contribuições fixas de recursos, com equivalência em valor financeiro, que compreendem a

infraestrutura total compartilhada $Q$, dado que 
$\sum_{i=1}^{n} x_{i} \leq Q$

O valor atribuído pelo agente $i$ para obtenção da parcela do recurso é designado por i. Esse valor compreende informação privada de cada agente, resultante de estratégias comerciais, formuladas sobre expectativas de ganhos individuais decorrentes de vantagens competitivas, crescimento da receita e lançamento de novos serviços, entre outros. A despeito do seu caráter privado, é conhecido, a priori, que i é uma parcela de uma variável aleatória com função distribuição Fi. Na prática Fi resume uma distribuição finita de possibilidades de i, associada ao tipo de organização e os limites da infraestrutura compartilhada.

Por sua vez, as características técnicas da infraestrutura compartilhada são conhecidas e podem ser monitoradas objetivamente pelos demais agentes. Abrange características como a quantidade de usuários, a disponibilidade de radiofrequências, o porte e o montante de recursos disponíveis para investimento, entre outros.

Para planejamento da constituição e uso da capacidade máxima da infraestrutura compartilhada, cada um dos diferentes agentes envolvidos declara suas projeções de uso $1, \ldots, \mathrm{n}$ do recurso. Trata-se, portanto, de uma informação exteriorizada pelos agentes no início do contrato e, desse modo, conhecida por todos os interessados e, eventualmente, monitorada pelo coordenador do sistema.

A presença de um coordenador do sistema, que pode ser uma entidade reguladora ou um conjunto de regras contratuais estabelecidas para fins de governança, tem a função de estabelecer os incentivos e limites do consórcio de participantes e mediar conflitos. Dentre suas atribuições, inclui o dimensionamento do recurso $Q$ de modo a maximizar o bem-estar social, tomando em consideração que o tamanho do recurso é fixo e seu compartilhamento tem um custo não desprezível. A constituição de um $Q$ ótimo pressupõe o conhecimento sobre o i. Assim, compete ao operador criar incentivos para que o agente $i$ declare o valor real de i, ex ante.

O arranjo deve ser suficientemente equilibrado para incentivar a participação, definir os níveis de compartilhamento e como os custos devem ser rateados. O desafio econômico de se compor uma estrutura compartilhada é a busca eficiente de um arranjo no qual cada organização participante se comporte estrategicamente no sentido de maximizar seu próprio benefício líquido Ei. Por benefício líquido entende-se a expectativa que cada organização tem pela redução de seus custos de implantação e operação advindos da utilização da infraestrutura própria, ou de terceiros, face aos custos de participação no arranjo compartilhado.

Nas soluções de compartilhamento mapeadas neste estudo é possível distinguir a coexistência de dois principais casos. O primeiro, abrange os arranjos com informação completa, que pressupõe o conhecimento completo dos agentes sobre os valores atribuídos 
ao recurso. i,t, para um dado ano $t$.

Trata-se de um caso específico que mimetiza a eficiência de Pareto (first best) na alocação de recursos quando produtos e serviços são comercializados em condição de livre mercado. Exemplos desse tipo de caso podem ser encontrados em acordos de compartilhamento de antenas e dutos, nos quais são declarados, no contrato, o uso do recurso por cada agente participante do arranjo.

O segundo caso abrange as circunstâncias em que os agentes não declaram suas informações privadas i. Trata-se, portanto, do caso com informação parcial, na qual o coordenador do sistema e os agentes econômicos conhecem antecipadamente apenas a distribuição Fi,t de i,t. Nessas condições os agentes agem de modo independente visando incrementos de seus benefícios individuais. Esse tipo de arranjo é comumente enquadrado na categoria de jogos não cooperativos, no qual o equilíbrio tem a maior eficiência possível, mas não necessariamente a melhor.

A segunda melhor alocação de recursos (second-best) pode ser alcançada com a imposição de regras ex ante. Exemplos desse tipo podem ser encontrados em acordos de interconexão, que utilizam regras de desbalanceamento de tráfego, ou em soluções RAN Sharing que, em regra, contemplam gatilhos de custo para volume de uso que exceda o limite contratado. Esse contexto justifica uma ação mais contundente de intervenção de um controlador central, que possui informações completas sobre as preferências do agente e que pode atuar na definição de regras e arbitragem para assegurar o correto funcionamento do sistema.

Com fundamento nessas definições, passa-se para o desenho do modelo geral. Por se tratar de uma representação introdutória para o contexto do compartilhamento de infraestruturas no setor, optou-se por generalizações sobre a disponibilidade de informações. Estudos futuros, com o uso de ferramentas de otimização, podem auxiliar na identificação de padrões de maximização das expectativas de benefícios líquidos obtidos pelas organizações engajadas em projetos dessa natureza.

\subsection{Os casos com informações completas}

O cenário base se refere a solução de compartilhamento com informação plena sobre os benefícios para cada agente envolvido. Trata-se, nesses termos, de um problema do rateio eficiente de uma determinada infraestrutura $Q$ que, para fins de ilustração, pode ser compreendido como um pool de estações de telefonia móvel composta por infraestruturas físicas, equipamentos e uma determinada faixa de radiofrequência associada. No caso $Q$ deve ser rateado entre todos os $n$ agente engajados no acordo de compartilhamento.

Tomando o custo de investimento e operação do sistema como $c(Q)$, estimado em função do porte e capacidade de $Q$, é possível assumir, para fins de simplificação, que $c(Q)=Q$. Ainda como referência, assume-se como unidade temporal o ano civil, denominado por $t$. Assim, se no ano $t$ um agente $i$ utilizar a fração xi do recurso obterá como utilidade i,tuxi. Cabe destacar que em muitos arranjos de compartilhamento, o custeio entre os participantes ci 
pode ocorrer mediante disponibilização de recursos outros que não se resumem a pagamentos em espécie.

Para planejamento da constituição e uso da capacidade máxima da infraestrutura, cada um dos diferentes agentes envolvidos, declaram suas projeções de uso $1, \ldots, \mathrm{n}$ ex ante. Trata-se de uma informação declarada pelos agentes no início do contrato e, portanto, conhecida por todos os agentes participantes do contrato e monitorada pelo coordenador do sistema.

No ano $t$, o valor de i,t é obtido do seguinte modo. Uma vez conhecida a projeção i, o agente $i$ compete por recursos da infraestrutura compartilhada, se logrado sucesso, tem-se que $i, t=i$, caso contrário $i, t=0$.

Vale notar que o coordenador do sistema para o presente modelo é uma entidade neutra(10), contratada para representar os incentivos do consórcio. Na prática essa entidade se ocupa da função de gerenciamento da infraestrutura, em obediência às políticas de compartilhamento definidas em contrato.

(10)Aos moldes do que ocorre para o contrato de Ran Sharing (Processos no 53500.017260/2015-34 e no 08700.010378/2015-94), disponível em:

https://sei.anatel.gov.br/sei/modulos/pesquisa/md_pesq_processo_pesquisar.php?acao_exter na=protocolo_pesquisar\&acao_origem_externa=protocolo_pesquisar\&id_orgao_acesso_exte rno $=0$

No cenário posto, com informação completa, o vetor $\theta=1, t, \ldots, n, t$ é conhecido pelo coordenador do sistema para cada ano $t$. À luz desses vetores, o coordenador pode maximizar o ganho geral do arranjo (benefício geral do sistema), definido por:

(equação 1)

$$
\sum_{i=1}^{n} \theta_{i, t} u\left(x_{i}\right)
$$

E o vetor de alocação ótimo é calculado com:

(equação 2)

$$
x(\theta)=\left(x_{1}(\theta), \ldots, x_{n}(\theta)\right)
$$




$$
\begin{gathered}
=\left\{\sum_{i=1}^{n} \theta_{i, t} u\left(x_{i}\right)\right\} \\
\text { d.q. } \sum_{i=1}^{n} x_{i} \leq Q
\end{gathered}
$$

A função indica que $x_{1}, \ldots, x_{n}$ maximiza $\sum_{i=1}^{n} \theta_{i, t} u\left(x_{i}\right)$ sob a condição de que $\sum_{i=1}^{n} x_{i} \leq Q$. Nesses termos, o benefício para o participante $i$ é dado por $\theta_{i, t} u\left(x_{i}\right)$. Se a infraestrutura é compartilhada para um determinado ano $t$, então é possível assumir que $\sum_{i} \theta_{i, t} u\left(x_{i}\right)>c(Q)=Q$, e o coordenador do sistema pode requisitar o pagamento $c_{i}$, de modo que $c_{i} \leq \theta_{i, t} u\left(x_{i}\right)$ e $\sum_{i} x_{i}=Q$. Naturalmente, se $\sum_{i} \theta_{i, t} u\left(x_{i}\right)<c(Q)$, não haverá sustentabilidade econômica para manutenção desse arranjo.

Para os casos em que um mesmo conjunto de participantes dividem a infraestrutura de modo contínuo, a computação da alocação ótima em cada ano $t$ é feita pela equação 2 mas o coordenador do sistema requisita o pagamento constante em cada ano $t$. $\mathrm{O}$ requisito que satisfaz o benefício líquido esperado $E$, para cada participante $i$, é dado por:

\section{(equação 3)}

$$
E\left[\theta_{i, t} u\left(x_{i}(\theta)\right)\right]-c_{i} \geq 0
$$


e $\sum_{i} x_{i}=Q$ sintetiza o custo da operação do mecanismo.

$\mathrm{Na}$ equação 3, o benefício líquido médio esperado pelo participante $i$ equivale ao resultado da alocação obtida com a equação 2 . Assim, se a equação 3 não pode ser satisfeita, então não é possível estimar $Q$. Cabe destacar que o custeio do contrato de compartilhamento pressupõe pagamentos $c_{i}$ pelo agente $i$ pela parcela utilizada $x_{i}$ do recurso $Q$.

O coordenador do sistema define o tamanho $Q$ levando em consideração que o tamanho do sistema não é fixo e é dimensionado a partir do custo que os agentes participantes estão dispostos a investir. O trabalho do coordenador pode ser sintetizado da seguinte maneira:

(equação 4)

$$
Q^{*}=\arg \max _{Q}\left\{E\left[\sum_{i} \theta_{i, t} u\left(x_{i}\right)\right]-c(Q)\right\}
$$

Tal intervenção busca alcançar o máximo possível eficiência econômica. Nessas condições, o coordenador do sistema busca um arranjo no qual o equilíbrio de Nash é um ponto no qual o sistema é o mais econômico possível. Esse ponto consiste em identificar as funções apropriadas na qual os pagamentos $c(\theta)=\left(c_{1}(\theta), \ldots, c_{n}(\theta)\right)$ equivale à alocação de recursos $x(\theta)=\left(x_{1}(\theta), \ldots, x_{n}(\theta)\right)$. No cenário de informação completa, $c(\theta)$ depende dos valores $\theta=\left(\theta_{1}, \ldots, \theta_{n}\right)$ declarados, e a alocação de recursos para o ano $t$, definido por $x\left(\theta_{1, t}, \ldots, \theta_{n, t}\right)$, depende de $\theta$ e da quantidade de agentes no ano $t$.

Nesse tipo de contrato, para atingir o equilíbrio almejado, é preciso obedecer a algumas condições fundamentais. A primeira diz respeito a já referida veracidade dos valores declarados de $\theta_{i}$, de 
modo que sejam fidedignos para todos os agentes envolvidos. O segundo trata da expectativa dos agentes de que os benefícios líquidos do arranjo superem os custos individuais de compartilhamento. Finalmente, a expectativa geral de que o benefício líquido total é maximizado para as escolhas de $Q$, x e c que satisfazem as demais condições.

\subsection{Os casos com informações incompletas}

A despeito dos benefícios do exercício com modelo elaborado a partir da uma hipótese de informação completa, na realidade i,t consiste em informação privada do agente $i$ que a trata de modo estratégico. Uma vez convidado a revelar i,t o agente tem como reação natural declarar um valor impreciso, menor que o de fato atribuído por ele, de modo a obter um compartilhamento maior de recursos a um custo inferior. É nesse ambiente que se opera, em regra, o jogo entre os agentes em busca da maximização de seus benefícios individuais.

De modo a incentivar a revelação do valor real de i,t o mediador tem a seu favor autonomia para estabelecer incentivos. Courcoubetis e Weber (2009) sugerem, sem serem exaustivos, a introdução de pagamentos cujo montante dependa dessas declarações ou uma taxa de associação indexada a i,t e suficiente para incentivar os participantes a declararem valores verdadeiros de i,t. Exemplos de incentivos recorrentes para o caso brasileiro incluem sobretaxas para o uso de recursos excedentes aos contratados e ônus pela saída prematura dos arranjos compartilhados.

Nessa configuração, o agente $i$ declara i,t de modo a maximizar sua expectativa de benefício líquido. Esse é um típico modelo do tipo Bayesian Nash Equilibrium no qual nenhum agente consegue melhorar sua expectativa de ganho de benefício líquido pela declaração unilateral de i,t. Nesse contexto, conforme preconizado por Courcoubetis e Weber (2009), o equilíbrio é alcançado mediante a satisfação das seguintes condições.

C1) Compatibilidade de incentivos: os agentes devem perceber que é do seu interesse declarar o valor verdadeiros de i,t.

C2) Racionalidade individual: os agentes devem perceber benefícios líquidos positivos da participação.

C3) Saldo orçamentário: os desembolsos realizados devem cobrir o custo do projeto $c(Q)$.

C4) O bem-estar social máximo esperado (benefício líquido total) é atingido quando C1-C3.

Para alcançar tal equilíbrio os autores sugerem duas alternativas. Na primeira, assume-se que $-i, t=1, t, \ldots, i-1, t, \ldots, 1+1, t, \ldots, n, t$. Assim, adotando-se uma perspectiva ex ante, 0 agente $i$, que atribui a utilidade -i,t ao sistema compartilhado, e assumindo como verdadeira as declarações de todos os demais agentes envolvidos, tem-se que o benefício líquido esperado por $i$ equivale a E-i,t, i.e.: 
(equação 5)

$$
E_{\theta_{-i, t}}=E\left[\theta_{i, t} u\left(x_{i}\left(\theta_{t}\right)\right)-c_{i}\left(\theta_{t}\right)\right] \geq 0
$$

De modo oposto, na perspectiva ex post e dado que as condições de $\theta_{i, t}, \theta_{-i, t}$ se preservam, a condição C2 se manifesta nos seguintes termos:

\section{(equação 6)}

$\theta_{i, t} u\left(x_{i}\left(\theta_{t}\right)\right)-c_{i}\left(\theta_{t}\right) \geq 0$

De modo semelhante, as perspectivas ex ante e ex post sobre $\mathrm{C} 3$ são, respectivamente

$$
E_{\theta}\left[c_{1}\left(\theta_{t}\right)+\ldots+c_{n}\left(\theta_{t}\right)\right] \geq c \text { e } c_{1}\left(\theta_{t}\right)+\ldots+c_{n}\left(\theta_{t}\right) \geq c
$$

O modelo sugere que a política de compartilhamento adotada pode induzir atuações distintas do agente $i$ acerca do valor atribuído ao recurso compartilhado e seu custeio. Desse modo, a forma como o recurso é alocado em um dado ano $t$, depende do histórico de declarações dos agentes.

\section{Considerações sobre políticas públicas setoriais à luz do desenho geral de mecanismo}

O desenho da política de compartilhamento desempenha um papel fundamental para sustentabilidade desse tipo de arranjo. Assim, dada sua complexidade exige diretrizes usualmente estabelecidas em contratos cujos termos contemplam as regras afetas ao dimensionamento do recurso a ser compartilhado, a contribuição individual de cada agente para seu custeio, o prazo do acordo e as contrapartidas onerosas, de permuta ou de garantias. A regulamentação, por sua vez, abrange as condições gerais de competição e compartilhamento, mediação, garantia da isonomia e resolução de conflitos, entre outros.

Uma política com tantas facetas busca, ao cabo, endereçar riscos de atuação oportunista 
pelos agentes ao contribuírem para o desenvolvimento do sistema compartilhado com uma parcela de recursos inferior ao socialmente desejável. Conforme ficou ilustrado no modelo geral, declarações imprecisas sobre o uso do sistema e o valor a ele atribuído e, por conseguinte, do seu custeio, tem o potencial de impactar o desempenho do compartilhamento e gerar conflitos para sua gestão e viabilidade econômica. Assim, o desafio é estabelecer regras que incentivem os agentes a declararem o valor do arranjo e disporem das contribuições apropriadas para constituição e manutenção da infraestrutura.

Exames qualificados sobre esses modelos ponderam pela existência de maior benefício líquido em arranjos com distribuição proporcional do recurso, com incentivos adequados à revelação das expectativas de ganhos pelos agentes e com a intervenção de regras contratuais e/ou mediada por um agente central (Frischmann 2005, Meddour et al. 2011). Nesse tocante, incentivos inadequados podem romper com a expectativa de ganho coletivo, resultando, nessas circunstâncias, em perda de eficiência do sistema e, por fim, a sobreposição do interesse individual já que cada agente busca maximizar seus ganhos individuais às custas da sustentabilidade do sistema posto.

O modelo geral proposto, ao citar a prática brasileira, faz apontamentos sobre eventuais incentivos para engajamento e retenção dos participantes. Exemplos recorrentes incluem a imposição de taxas de associação, sobretaxa pelo uso de recurso excedente ao contratado ou a imposição de garantias de priorização para os agentes que contribuam com mais recursos. O resultado pretendido é uma instalação dimensionada para atender os consorciados e otimizar o uso do recurso.

Conforme ficou demonstrado, o desenvolvimento das estratégias de compartilhamento inaugurou uma nova linha de estudos sobre o setor de telecomunicações. Esses mecanismos têm como principal objetivo a otimização dos custos de investimento e operação e a eficiência no uso de recursos escassos.

Na perspectiva do formulador de políticas públicas, contempla, também, a redução de barreiras competitivas com efeito sobre a promoção da universalização de serviços de telecomunicações. É sobre esse ponto que se pode vislumbrar particular repercussão das iniciativas de compartilhamento, notadamente no tocante aos objetivos de universalização e massificação dos serviços de telecomunicações.

Cabe ressaltar, ainda no plano das políticas públicas, que a difusão desses arranjos compartilhados também exige adaptações por parte das autoridades regulatórias, das instâncias recursais e de arbitragem. Por um lado, no exercício de seu domínio, podem atuar de modo a estabelecer incentivos adequados à promoção e sustentabilidade do compartilhamento e, por outro, devem adequar suas expertises e desenvolver ferramentas e métodos de arbitragem e mediação afetos ao tema de compartilhamento.

Tais reflexões reforçam a necessidade de novos estudos e análises de exemplos práticos e medições numéricas sobre o desempenho das atuais políticas de compartilhamento. Avanços 
no debate introduzido neste estudo são necessários a fim assegurar o caráter evolucionário da modelagem e refinar seus resultados de modo a adequá-los para implementações práticas, na forma de contratos ou regulamentos de compartilhamento de infraestruturas no Brasil. Esforços nesse sentido incluem a sofisticação dos modelos propostos, com mais de dois participantes, e a especificação de parâmetros de governança, visando mitigar a incidência de conluio ou outras práticas prejudiciais à competição e à sustentabilidade dos arranjos de compartilhamento.

\section{Conclusões}

O presente estudo aborda a questão do compartilhamento de infraestruturas no setor de telecomunicações brasileiro. O debate se inicia com a apresentação de um inventário dos principais arranjos de compartilhamento, contemplando suas principais características, conforme disposto nos regulamentos e contratos públicos disponíveis. Compreende, ainda, um breve levantamento dos seus fundamentos legais e regulatórios, motivações e limitações.

Em seguida, com fundamento nos termos do inventário, elaborou-se um modelo geral de compartilhamento. O modelo busca elucidar alguns dos mecanismos fundamentais que regem os arranjos de compartilhamento no setor de telecomunicações de modo a evidenciar a dimensão dos seus potenciais e benefícios. Premissas de informações completas e incompletas prestadas pelos agentes envolvidos e a presença de um coordenador geral são elementos adicionais do desenho do modelo. Por fim, e à luz do debate posto, são debatidos aspectos das políticas de compartilhamento, com foco nos incentivos para promoção da eficiência dos arranjos e maximização da utilidade dos recursos escassos.

O estudo permite derivar uma série de argumentos para fins de aperfeiçoamento de políticas públicas. Nesse tocante, faz reflexões sobre a criação de incentivos voltados à maximização dos benefícios do compartilhamento e otimização da alocativos de recursos escassos. Tais condições são essenciais para a expansão da oferta de serviços de telecomunicações em regiões desassistidas de infraestruturas, notabilizadas pela baixa atratividade econômica.

Tais atributos ganham especial ênfase no contexto de crise que acompanha a epidemia de coronavirus. Essas circunstâncias revelam, por um lado, o crescimento pela demanda e uso de serviços de telecomunicações e, por outro, restrição de liquidez para investimentos em infraestruturas. Soluções de compartilhamento têm o potencial de racionalizar custos com investimento e manutenção e, ao mesmo tempo, permitir a introdução de novos agentes competitivos no setor. Com particular impacto para a demanda, o compartilhamento, ao reduzir os custos, possibilita aos prestadores de serviço ampliarem sua atuação em regiões de menor atividade econômica, oportunizando, dessa forma, a ampliação do acesso para populações de menor renda. 


\section{Referências bibliográficas}

Aguiar, Marcos, Julio Bezerra, Nuna Gomes, Maikel Wilms e Eduardo Canabarro. 2016. 10 Princípios para o Desenho do Novo Modelo Regulatório de Telecomunicações: Promoção de Equilíbrio e Incentivo Econômico para Viabilizar o Investimento Sustentável em Infraestrutura no Brasil. São Paulo: Boston Consulting Group.

Anatel - Agência Nacional de Telecomunicações. 1998. Resolução no 40, de 23 de julho de 1998: (REVOGADA) Aprova o Regulamento Geral de Interconexão. Brasília: Anatel.

Anatel - Agência Nacional de Telecomunicações. 1999. Resolução Conjunta no 1, de 24 de novembro de 1999: Aprova o Regulamento Conjunto para Compartilhamento de Infraestrutura entre os Setores de Energia Elétrica, Telecomunicações e Petróleo. Brasília: Anatel.

Anatel - Agência Nacional de Telecomunicações. 2005. Resolução no 410, de 11 de julho de 2005:(REVOGADA) Aprova o Regulamento Geral de Interconexão. Brasília: Anatel.

Anatel - Agência Nacional de Telecomunicações. 2007. Resolução no 477, de 7 de agosto de 2007: Aprova o Regulamento do Serviço Móvel Pessoal - SMP. Brasília: Anatel.

Anatel - Agência Nacional de Telecomunicações. 2016. Resolução no 671, de 3 de novembro de 2016:Aprova o Regulamento de Uso do Espectro de Radiofrequências e altera o Regulamento de Cobrança de Preço Público pelo Direito de Uso de Radiofrequências e o Regulamento de Aplicação de Sanções Administrativas. Brasília: Anatel.

Anatel - Agência Nacional de Telecomunicações. 2010. Resolução no 550, de 22 de novembro de 2010: Aprova o Regulamento sobre Exploração de Serviço Móvel Pessoal SMP por meio de Rede Virtual (RRV-SMP). Brasília: Anatel.

Anatel - Agência Nacional de Telecomunicações. 2017. Resolução no 683, de 05 de outubro de 2017: Aprova o Regulamento de Compartilhamento de Infraestrutura de Suporte à Prestação de Serviço de Telecomunicações. Brasília: Anatel.

Anatel - Agência Nacional de Telecomunicações. 2018a. Resolução no 693, de 17 de julho de 2018: Aprova o Regulamento Geral de Interconexão - RGI e altera o Regulamento dos Serviços de Telecomunicações, o Regimento Interno da Anatel e os Regulamentos de Remuneração pelo uso de redes do Serviço Telefônico Fixo Comutado e do Serviço Móvel Pessoal. Brasília: Anatel.

Anatel - Agência Nacional de Telecomunicações. 2018b. Resolução no 694, de 17 de julho de 2018: Altera o Plano Geral de Metas de Competição - PGMC e dá outras providências. Brasília: Anatel.

Anatel - Agência Nacional de Telecomunicações. 2019. Manual Operacional de Compartilhamento de Infraestrutura. Brasília: Anatel. 
Brasil. 1997. Lei no 9.472, de 16 de julho de 1997: Dispõe sobre a organização dos serviços de telecomunicações, a criação e funcionamento de um órgão regulador e outros aspectos institucionais, nos termos da Emenda Constitucional no 8, de 1995. Brasília: Congresso Nacional.

Cade - Conselho Administrativo de Defesa Econômica. 2016. Resolução no 17, de 18 de outubro de 2016: Disciplina as hipóteses de notificação de contratos associativos de que trata o inciso IV do artigo 90 da Lei $n^{-}$12.529, de 30 de novembro de 2011 e revoga a Resolução Cade no 10 , de 29 de outubro de 2014. Brasília: CADE.

Presidência da República. 2003. Decreto no 4.733, de 10 de junho de 2003: Dispõe sobre políticas públicas de telecomunicações e dá outras providências. Brasília: Casa Civil.

Courcoubetis, Costas e Richard Weber. 2009. Economic issues in shared infrastructures. VISA Workshop, Barcelona, August.

Freitas, Luciano Charlita, Flávio Fagundes Ferreira, Humberto Bruno Silva e Leonardo Morais. 2017, 2018. Análise da alocação de recursos públicos para universalização da banda larga no Brasil. Pesquisa sobre o uso das tecnologias de informação e comunicação nos domicílios brasileiros. São Paulo: TIC domicílios.

Frischmann, Brett. M. 2005. An economic theory of infrastructure and commons management. Minnesota law review (4), pp. 917-1130.

Fudenberg, Drew e Jean Tirole. 1991. Game Theory. Cambridge: MIT Press.

Garcia, Jose Marino e Tim Kelly. 2015. The economics and policy implications of infrastructure sharing and mutualisation in Africa. Washington: World Bank, World Development Report 2016: Digital Dividends.

Lefèvre, Camila Borba. 2008. Mobile Sharing. Proceedings of 8th International ITU Global Symposium of Regulators, Phuket.

LCA. 2018. Considerações sobre compartilhamento de infraestrutura entre o setor de telecomunicações e de distribuição de energia elétrica. Nota Técnica - Consulta Pública Anatel no 28/2018 e ANEEL no 16/2018 (Tomada de Subsídios para AIR). São Paulo: LCA.

Meddour, Djamal-Eddine, Tinku Rasheed e Yvon Gourhant. 2011. On the role of infrastructure sharing for mobile network operators in emerging markets. Computer Networks 55, pp. 1576-1591.

Myerson, Roger. 2008. Perspectives on Mechanism Design in Economic Theory. American Economic Review, 98(3), pp. 586-603.

Nisan, Noam e Amir Ronen. 2001. Algorithmic mechanism design. Games and Economic Behavior 35, pp. 166-196. 
Samanez, Patricia. 2018. A legalidade da Resolução Conjunta ANEEL, ANATEL e ANP $n^{0} 4$, que fixou um preço de referência para o compartilhamento de infraestrutura e o impacto desta Resolução nos contratos de concessão de distribuição de energia elétrica. São Paulo: FGV Direito SP.

Sidenbladh, Thomas. 2002. License and regulatory update on UMTS. Moscow: UMTS Forum.

\section{Biografía de los Autores}

Luciano Charlita de Freitas: Especialista em Regulação e Doutor em Políticas de Desenvolvimento pela Universidade de Hiroshima, Japão.

Tiago Sousa Prado: Especialista em Regulação e Doutorando em Informação e Mídia pela Universidade Estadual de Michigan, Estados Unidos.

Agostinho Linhares de Souza Filho: Especialista em Regulação e Doutor em Telecomunicações pela Universidade de Brasília, Brasil.

Ronaldo Neves de Moura Filho: Especialista em Regulação e Mestrando em Administração Pública pelo Instituto Brasiliense de Direito Público, Brasil.

Carlos Manuel Baigorri: Especialista em Regulação e Doutor em Economia pela Universidade Católica de Brasília, Brasil.

Leonardo Euler de Morais: Especialista em Regulação e Mestre de Economia pela Universidade de Brasília, Brasil. 